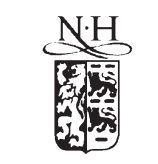

ELSEVIER
Journal of International Money and Finance

19 (2000) 185-205
Journal of

International

Money

and Finance

\title{
Endogenous real exchange rate fluctuations in an optimizing open economy model
}

\author{
Shikuan Chen *
}

Department of International Business, National Taiwan University, Republic of Taipei, Taiwan, ROC

\begin{abstract}
This paper constructs a simple intertemporal model of a small open economy inhabited by forward looking agents, in which endogenous fluctuations in the real exchange rate can arise in equilibrium, i.e. fluctuations that are not linked to movements in economic fundamentals. The key condition for the main results is the assumption that the Marshall-Lerner condition does not hold (i.e. that the country's exports and imports are inelastic to its real exchange rate). It is shown that, given that the Marshall-Lerner condition fails, there exist periodic equilibria and/or stationary sunspot equilibria in the neighborhood of the stationary state. (C) 2000 Elsevier Science Ltd. All rights reserved.
\end{abstract}

Keywords: Endogenous fluctuations; Periodic cycles; Hopf bifurcation; Sunspot equilibrium

\section{Introduction}

In international macroeconomics, perhaps the most striking features of the data are the large, persistent fluctuations in nominal and real exchange rates. The large volatility of these rates has stimulated the development of various versions of the so-called exchange rate overshooting theory pioneered by Dornbusch (1976), who developed a model in which a monetary expansion induces an immediate depreciation of domestic money in excess of its long-run equilibrium value, i.e. an overshooting of the exchange rate due to an exogenous shock. Subsequent studies (e.g. Calvo and Rodriguez, 1977; Liviatan, 1981; Frenkel and Rodriquez, 1982; Chen et al., 1989), almost without exception, also attributed large fluctuations in the real exchange rate to exogenous shocks and regarded the wide variability of the real exchange rate as purely a transitory process by which asset holders restore portfolio

\footnotetext{
* Corresponding author. Tel.: +886-2-3638399; fax: +886-2-3638399.
} 
balance in the new steady state. In this class of models in which a unique equilibrium path tending toward the steady state is ensured, no persistent fluctuations in the real exchange rate could occur in a stationary economy which does not experience any exogenous shock to its economic fundamentals. Fluctuations in real exchange rates are therefore ascribed to fluctuations in underlying fundamental economic variables.

Meese and Rogoff (1983) first challenged the explanatory power of existing 'exogenous' models of exchange rate determination by showing their inferior outof-sample forecasting performance relative to a simple random walk model. Many empirical studies since then have seemed to end with the conclusion that the real exchange rate also follows a random walk. However, a failure of structural models to outperform a random walk model does not necessarily mean that the exchange rate follows a random walk. In fact, recently a BDS test for exchange rate changes has actually rejected the random walk hypothesis and indicates that exchange rates contain substantial nonlinearity (Hsieh, 1989; Brock et al., 1991).

One plausible explanation of the nonlinear dependence is that exchange rate fluctuations are endogenous to an important degree. Over the past decade there has been a revival of interest in endogenous models of economic fluctuations, in which fluctuations could persist even in the absence of exogenous shocks to the economy. ${ }^{1}$ Following this line of research, the present paper investigates the stability of real exchange rate dynamics in the context of an endogenous cycle model. The Brock (1975) model is modified and extended to a fully-employed small, open economy under flexible exchange rates, in which residents who optimize with perfect foresight consume both domestic goods and imported goods. Currency substitution does not exist in the economy and national money is used solely for purchases of goods and assets. The non-monetary assets in the economy are the fixed stock of domestic equities and international bonds denominated in foreign currency. These two different types of assets are assumed to be imperfect substitutes. In the analysis which follows, it is assumed that the utility function of the agent is separable in bond balances and consumption goods. It is shown that even such a simple model can produce cyclical dynamic paths for the real exchange rate. The condition for such cyclical equilibria to occur is that the Marshall-Lerner condition is not satisfied in the short run. When the Marshall-Lerner condition does not hold, a real exchange rate depreciation worsens the balance of trade, which has to be accompanied, in equilibrium, by an increase in capital inflow or a reduction in capital outflow, which, in turn, requires a fall in the expected rate of real depreciation of the domestic currency. Thus, the possibility of monotonic movements and dynamic saddle paths is excluded and cyclical fluctuations in the real exchange rate can arise. As the condition that the import and export demands are inelastic in the short run is well established empirically, ${ }^{2}$

\footnotetext{
${ }^{1}$ See Boldrin and Woodford (1990) for an excellent survey of endogenous fluctuations models. They point out that 'endogenous cycle models are essentially nonlinear' (p. 190).

${ }^{2}$ Krugman and Obstfeld (1997, p. 485) reproduce IMF elasticity estimates for trade in manufactured goods. For most industrialized countries, the 'impact' elasticities, which measure the response of trade flows to relative price changes in the first six months, 'are so small that the sum of the impact export and import elasticities is less than 1'.
} 
the result we obtain in this paper may explain the short-run fluctuations in real exchange rates.

\section{The model}

This paper's framework is similar to Auernheimer's (1987), except in the treatment of the real rate of interest and the number of commodities consumed. The economy produces a constant flow of a single commodity, $\bar{y}$, with the aid of a fixed stock of physical capital. The price of domestic output, $p_{t}$, is freely flexible, as is the exchange rate, $e_{t}$. The subscript $t$ denotes time throughout this paper. Each resident consumes both the domestic good and the imported good. The economy is 'small' in that it cannot influence the foreign currency price of the imported good, $p^{f}$. A country's real exchange rate, $q_{t}$, is defined as the relative purchasing power of domestic output: $q_{t}=\frac{e_{t} p^{f}}{p_{t}}$ (Kenen, 1985, p. 331). This is called the terms of trade in trade theory. The economy is 'large' in that it can influence the terms of trade.

Each resident holds domestic money, $M_{t}$, to finance his purchase of current consumption and investment in foreign bonds. Under flexible exchange rates, national paper money, however, "is not a reserve for the state as a whole, even though it is a reserve for a typical individual within the state" (Mundell, 1973, p. 114). The residents are therefore allowed to hold foreign assets or incur foreign liabilities. ${ }^{3} \mathrm{We}$ shall assume that the economy is an interest-rate taker in the world capital market. Residents at home can borrow from and lend to foreigners at the given rate, $i^{*}$. The ownership of the fixed stock of physical capital which produces the fixed flow of output provides another asset which may be held. As the stock is fixed, its real rate of return, $r$, is also fixed and can be assumed to be equal to the subjective rate of discount, i.e., $r=1 / \beta-1$ or $1+r=1 / \beta$. For simplicity of analysis, it is further assumed that foreigners hold zero stocks of domestic securities (equities). The stock of capital being fixed also makes its inclusion in individuals' budget constraints of no consequence, and it disappears when aggregation is performed (Auernheimer, 1987, p. 282).

In contrast to the sticky-price monetary model in which perfect asset substitutability is assumed, this paper assumes that foreign bonds and domestic securities are imperfect substitutes. As Frankel (1983, p. 96) observed, "there are many reasons why two assets can be imperfect substitutes: liquidity, tax treatment, default risk, political risk, and exchange risk." Residents at home may prefer to hold foreign bonds because foreign bonds are considered to be a 'safe haven', subject to less default risk and political risk. Likewise, foreign bonds may be considered to be riskier or less liquid. To represent this feature, we let net holdings of foreign bonds

${ }^{3}$ Mundell (1973) was the first to formally tie the choice of exchange rate regime to its implications for risk allocation, as pointed out by Obstfeld (1997, p. 20). However, Helpman and Razin (1982) argued that Mundell's model does not allow international capital flows in a floating exchange rate regime. 
enter the utility function directly. Sargent (1987, section 4.3) let government debt enter the utility function directly on the grounds that "individuals prefer to hold government debt rather than private debt." Under conditions of an exogenously given rate of time preference and a constant rate of interest, the problem of the existence of a long-run equilibrium can be solved only by allowing bonds to enter individuals' utility functions, as in Calvo (1980). ${ }^{4}$ Otherwise, either agents' subjective rates of time preference have to be allowed to be endogenously determined as in Obstfeld (1981), or the rate of interest has to be assumed to be variable as in Auernheimer (1987) and Calvo (1991).

The representative resident with rational expectations is assumed to maximize the expected value of his lifetime utility:

$$
E_{t} \sum_{s=t}^{\infty} \beta^{s-t}\left[U_{1}\left(c_{1 s}\right)+U_{2}\left(c_{2 s}\right)+V\left(q_{s} B_{s}\right)\right] \quad 0<\beta<1,
$$

where $\beta$ is the subjective time discount rate on future utility; $U_{1}$ is the one-period utility from domestic good consumption, $c_{1 t} ; U_{2}$ is the one-period utility from imported good consumption, $c_{2 t}$; and $V$ is the one-period utility from the non-pecuniary services provided by international claims denominated in foreign currency, $B_{t}$. Note that $B_{t}$ may be positive or negative. The operator $E_{t}$ is a mathematical conditional expectation - a probability-weighted average of possible outcomes conditional on all information available up to date $t$.

In maximizing Eq. (1), the resident is bound by two constraints. The first is a flow budget constraint:

$$
q_{t}\left(B_{t}-B_{t-1}\right)+\frac{M_{t}^{d}-M_{t-1}}{p_{t}}=\bar{y}-c_{1 t}-q_{t} c_{2 t}+q_{t} i^{*} B_{t-1},
$$

where $M_{t}^{d}$ is the desired nominal money stock at the end of period $t$, with the superscript denoting demand, and $i^{*} B_{t-1}$ is the interest earned in foreign currency at the end of the $t-1$ period. The second constraint is a simple cash-in-advance constraint:

$$
\frac{M_{t-1}}{p_{t}} \geq c_{1 t}+q_{t} c_{2 t}+q_{t}\left(B_{t}-B_{t-1}\right)-q_{t} i^{*} B_{t-1}
$$

This cash-in-advance constraint is akin to that given in Feenstra (1985) and less general than that used by Grandmont and Younes (1972, 1973). The agent faces one single liquidity constraint on the purchase of both goods and bonds on the assumption that the goods market and the bonds market are the same and not segmented. Since domestic currency is the only asset used in transactions, it is needed for buying exported goods, imported goods, and foreign bonds and also for paying interest to foreigners. Note also that since the bonds transactions can be completed promptly,

\footnotetext{
${ }^{4}$ I thank Chau-nan Chen for suggesting that bonds in utility be used to solve the problem of the existence of a long-run equilibrium.
} 
the proceeds from selling bonds and interest earnings can be used immediately for consumption in the same period.

Let $\lambda_{t}$ and $\gamma_{t}$ be the multipliers associated with Eqs. (2) and (3), respectively, at time $t$. The first-order conditions for the maximization are

$$
\begin{aligned}
& U_{1}^{\prime}\left(c_{1 t}\right)=\lambda_{t}+\gamma_{t}, \\
& U_{2}^{\prime}\left(c_{2 t}\right)=\lambda_{t} q_{t}+\gamma_{t} q_{t}, \\
& V^{\prime}\left(q_{t} B_{t}\right)=\left(\lambda_{t}+\gamma_{t}\right)-\beta\left(1+i^{*}\right) E_{t}\left(\lambda_{t+1}+\gamma_{t+1}\right) \frac{q_{t+1}}{q_{t}}, \\
& \lambda_{t}=\beta E_{t} \frac{p_{t}}{p_{t+1}}\left(\lambda_{t+1}+\gamma_{t+1}\right),
\end{aligned}
$$

and, of course, the budget constraint (2) and the binding cash-in-advance constraint (3). An explicit solution is obtained most expeditiously by assuming that:

(A1) The marginal utility of consumption of exported goods, $U_{1}^{\prime}$, is constant and accordingly $\lambda_{t}+\gamma_{t}$ and $E_{t}\left(\lambda_{\mathrm{t}+1}+\gamma_{\mathrm{t}+1}\right)$ are constant. By an appropriate choice of units, we set $U_{1}^{\prime}=1$, that is,

$$
U_{1}\left(c_{1 t}\right)=c_{1 t},
$$

and accordingly $\lambda_{t}+\gamma_{t}$ and $E_{t}\left(\lambda_{t+1}+\gamma_{t+1}\right)$ is set to equal unity.

(A2) The utility function of imported good consumption is of the form:

$$
U_{2}\left(c_{2 t}\right)=\frac{h c_{2 t}^{1-a}}{1-a}, a>0, h>0 .
$$

(A3) Assuming that individuals are risk averters, the utility function of foreign bond holdings can be written as a quadratic function:

$$
V\left(q_{t} B_{t}\right)=\phi q_{t} B_{t}-\frac{\alpha\left(q_{t} B_{t}\right)^{2}}{2}, \alpha>0 .
$$

If residents prefer foreign bonds to domestic securities, $\phi>0$; if, on the contrary, domestic securities are preferred to foreign bonds, $\phi<0$.

Under the above set of assumptions, the first-order conditions (4)-(7) can be written as

$$
\begin{aligned}
& U_{1}^{\prime}\left(c_{1 t}\right)=1, \\
& U_{2}^{\prime}\left(C_{2 t}\right)=h c_{2 t}^{-a}=q_{t}, \\
& V^{\prime}\left(q_{t} B_{t}\right)=\phi-\alpha q_{t} B_{t}=1-\beta\left(1+i^{*}\right) E_{t} \frac{q_{t+1}}{q_{t}},
\end{aligned}
$$

and 


$$
\lambda_{t}=\beta E_{t} \frac{p_{t}}{p_{t+1}}
$$

which leads to $\gamma_{t}=1-\lambda_{t}=1-\beta E_{t} \frac{p_{t}}{p_{t+1}}$. In order for the model to have well-defined dynamics, we assume that $E_{t} \frac{p_{t}}{p_{t+1}}<\frac{1}{\beta}$, i.e. the expected gross rate of deflation has to be less than $1 / \beta .^{5}$

From (9) we obtain the demand for imports,

$$
c_{2 t}=s q_{t}^{-\frac{1}{a}}
$$

where $s=h_{a}^{\frac{1}{a}}>0$. Due to the small country assumption, the imported goods market clears at each moment of time. Residents in the home country are always able to obtain whatever quantity of imports they want at the given real exchange rate. The quantity of imports is solely demand determined.

The constancy of the marginal utility from consumption of domestic goods implies that domestic consumption of exported goods is simply a residual and the quantity of exports is also demand determined. The foreigners import whatever quantity they want from the home economy at the given real exchange rate; residents at home simply consume whatever quantity of domestic goods is left, $c_{1 t}=\bar{y}-X_{t}^{d}\left(q_{t}\right)$, where $X_{t}^{d}$ is the foreign demand for imports (home exports). For symmetry, we write the foreign demand for imports as

$$
X_{t}^{d}\left(q_{t}\right)=q_{t}^{\frac{1}{b}}, \quad b>0
$$

by assuming that the foreign residents have a similar utility function. Combining (12) and (13), we can write the balance of trade in terms of import goods, $T_{t}$, as

$$
T_{t}=\frac{x_{t}^{d}}{q_{t}}-c_{2 t}=q_{t}^{\frac{1-b}{b}}-s q_{t}^{-\frac{1}{a}} .
$$

For brevity of analysis, we assume in this paper that $q^{*}=1$ and hence $X\left(q^{*}\right)=1$ in the steady state. Thus, $T\left(q^{*}\right)=q^{*} T\left(q^{*}\right)=1-s \gtrless 0$ as $s \lessgtr 1$, where $s$ stands for the volume of imports as well as the ratio of imports to exports. The general condition for exchange market stability, referred to as the Marshall-Lerner condition, if examined in terms of imported goods, $T\left(q_{t}\right)$, is therefore expressed as

$$
\left.\frac{q_{t} \partial T\left(q_{t}\right)}{X_{t} / q_{t} \partial q_{t}}\right|_{q} ^{*}=s \frac{1}{a}+\frac{1}{b}-1 .
$$

However, if examined in terms of exported goods, $q_{t} T\left(q_{t}\right)$,

$$
\left.\frac{q_{t} \partial q_{t} T\left(q_{t}\right)}{X_{t} \partial q_{t}}\right|_{q} ^{*}=s \frac{1}{a}+\frac{1}{b}-s .
$$

\footnotetext{
5 A similar assumption is made by Fukuda (1993).
} 
The two conditions are the same only in the case of initial balanced trade $(s=1)$. If the trade balance is initially in deficits $(s>1)$, a real depreciation of domestic currency may improve the trade balance in terms of imported goods but worsen it in terms of exported goods. ${ }^{6}$ This will happen when $1<s \frac{1}{a}+\frac{1}{b}<s$.

Under the assumption of perfect foresight, i.e., $E_{t} q_{t+1}=q_{t}$, we can derive from (10) the real demand (in terms of domestic goods) for foreign bonds as

$$
q_{t} B_{t}=\frac{\phi}{\alpha}+\frac{\beta\left(1+i^{*}\right)\left(q_{t+1} / q_{t}\right)-1}{\alpha}
$$

The net real demand for foreign bonds consists of two separate components. The first term in Eq. (17) is the optimum risk-allocating component. The second term represents the expected yield component. It depends on expected yield differentials. (Note that we have assumed previously that the gross rate of return on domestic securities, $(1+r)$, is equal to $1 / \beta$.) In the steady state, $q_{t}=q_{t+1}=q^{*}$ and accordingly

$$
q^{*} B^{*}=\frac{\phi}{\alpha}+\frac{\beta\left(1+i^{*}\right)-1}{\alpha}
$$

Suppose it so happens that structurally $i^{*}=r=\frac{1}{\beta}-1$, then the above equation reduces to $q^{*} B^{*}=\frac{\phi}{\alpha}$. If $\phi>0$, then $q^{*} B^{*}>0$. Residents at home will hold a certain amount of 0 foreign bonds even though the real rate of return on foreign bonds is the same as that on domestic securities because foreign bonds are considered to be safer or more liquid. On the other hand, if $\phi<0$, then $q^{*} B^{*}<0$. Residents would rather incur foreign liabilities because foreign bonds are riskier or less liquid. In both cases, portfolio risk allocation is improved by holding some foreign bonds or incurring some foreign liabilities.

The outflow of capital, $K_{t}$, is defined as an increase in net holdings of foreign bonds

$$
K_{t}=B_{t}-B_{t-1} \text {. }
$$

Thus,

$$
K_{t}=\left(\frac{(\phi-1)}{\alpha q_{t}}+\frac{\beta\left(1+i^{*}\right) q_{t+1}}{\alpha q_{t}^{2}}\right)-\left(\frac{(\phi-1)}{\alpha q_{t-1}}+\frac{\beta\left(1+i^{*}\right) q_{t}}{\alpha q_{t-1}^{2}}\right) .
$$

Under a flexible exchange rate regime, equilibrium in the balance of payments is

\footnotetext{
${ }^{6}$ Note that the right-hand side of Eq. (16) can be rewritten as $s\left(\frac{1}{a}+\frac{1}{s b}-1\right)$. The expression in the parentheses is $\left.\frac{q_{t} \partial q_{t} T\left(q_{t}\right)}{q_{t} c_{2 t} \partial q_{t}}\right|_{q} ^{*}$. Thus, it is possible that $\frac{1}{a}+\frac{1}{b}>1$ but $\frac{1}{a}+\frac{1}{s b}<1$ when $s>1$.
} 
attained when the trade balance $T_{t}$, the service account $i^{*} B_{t-1}$, and the capital account $K_{t}$ sum up to zero.

$$
\begin{aligned}
& T_{t}+i^{*} B_{t-1}-K_{t}=q_{t} \frac{1-b}{b}-s q_{t}^{-\frac{1}{a}}-\left(\frac{\phi-1}{\alpha q_{t}}+\frac{\beta\left(1+i^{*}\right) q_{t+1}}{\alpha q_{t}^{2}}-\frac{(\phi-1)\left(1+i^{*}\right)}{\alpha q_{t-1}}-\frac{\left.\beta\left(1+i^{*}\right)^{2} q_{t}\right)}{\alpha q_{t-1}^{2}}\right) \\
& =0 .
\end{aligned}
$$

In the absence of central bank intervention, the balance of payments always balances. After rearrangement, (21) can be rewritten as a nonlinear difference equation of $q$ of second order,

$$
q_{t+1}=\frac{\alpha q_{t}^{2}}{\beta\left(1+i^{*}\right)}\left(q_{t}^{\frac{1-b}{b}}-s q_{t}^{-\frac{1}{a}}\right)-\frac{(\phi-1) q_{t}}{\beta\left(1+i^{*}\right)}+\frac{(\phi-1) q_{t}^{2}}{\beta q_{t-1}}+\frac{\left(1+i^{*}\right) q_{t}^{3}}{q_{t-1}^{2}} .
$$

Given the price flexibility, and other features of the model, money is neutral even in the short run.

Since national money is used solely for purchases of exportables, imported goods, and assets,

$$
\begin{aligned}
& M_{t-1}=p_{t}\left(\bar{y}-X_{t}^{d}\right)+e_{t} c_{2 t}+e_{t}\left(B_{t}-B_{t-1}\right)-e_{t} i^{*} B_{t-1} . \\
& =p_{t} \bar{y}-e_{t}\left(T_{t}-K_{t}+i^{*} B_{t-1}\right)
\end{aligned}
$$

and since the balance of payments always balances under flexible exchange rates, $T_{t}+i^{*} B_{t-1}-K_{t}=0$, we therefore obtain

$$
M_{t-1}=p_{t} \bar{y} \text {. }
$$

When the cash-in-advance constraint (3) binds, then substituting that condition into the household's budget constraint (2) implies that $M_{t}^{d}=p_{t} \bar{y}$. This suggests that the desired nominal stock of money at the end of period $t, M_{t}^{d}$, is equal to the existing stock of money, $M_{t-1}$. In order for the domestic price to attain steady-state equilibrium, the money supply is assumed to be constant.

\section{Existence of periodic equilibria}

In this section, we apply the theory of Hopf bifurcation to derive conditions for generating cyclic or periodic equilibria for the real exchange rate.

For simplicity of analysis, we assume that the real rate of return on domestic securities, $1 / \beta-1$, is equal to that on foreign bonds, $i^{*}$, in the stationary state so that $\beta\left(1+i^{*}\right)=1$. Furthermore, since $K^{*}=0$, it follows that $i^{*} \phi / \alpha=(1-s)$, that is, net foreign interest income (payments) is equal to net imports (exports). Under these conditions, linearization of (22) around the stationary state with $q^{*}=1$ yields

$$
\left[\begin{array}{l}
q_{t}-q^{*} \\
q_{t+1}-q^{*}
\end{array}\right]=J\left[\begin{array}{l}
q_{t-1}-q^{*} \\
q_{t}-q^{*}
\end{array}\right]
$$

where $J$ is the Jacobian matrix of the system of Eq. (22) and can be written as 


$$
J=\left[\begin{array}{ll}
0 & 1 \\
-\left(1+i^{*}\right)(1+\phi) & 1+\left(1+i^{*}\right)(1+\phi)+\frac{\epsilon}{\sigma}
\end{array}\right],
$$

with the characteristic equation

$$
\lambda^{2}-\gamma \lambda+\Delta=0
$$

and

$$
\begin{aligned}
& \gamma=\lambda_{1}+\lambda_{2}=1+\left(1+i^{*}\right)(1+\phi)+\frac{\epsilon}{\sigma}, \\
& \Delta=\lambda_{1} \lambda_{2}=\left(1+i^{*}\right)(1+\phi),
\end{aligned}
$$

where

$$
\begin{aligned}
& \sigma=\frac{\left(\frac{q_{t+q}}{q_{t}}\right)}{X_{t}} \partial\left(\frac{q_{t+1}}{q_{t}}\right)^{K_{t}, c_{2}^{*}}=\frac{\beta\left(1+i^{*}\right)}{\alpha}=\frac{1}{\alpha}, \\
& \epsilon=\frac{q_{t} \partial q_{t} T_{t}}{X_{t} \partial q_{t}} \mid q^{*}=s \frac{1}{a}+\frac{1}{b}-s .
\end{aligned}
$$

$\sigma$ is the elasticity of the capital outflow with respect to the gross rate of change in the real exchange rate evaluated at the stationary equilibrium. It also measures the degree of asset substitutability as is evident from Eq. (17). $\epsilon$ is the trade balance elasticity with respect to the real exchange rate, as already referred to in (16).

The magnitude of the two eigenvalues, $\lambda_{1}$ and $\lambda_{2}$, will vary according to the magnitude of $\gamma$ and $\Delta$. We first consider the benchmark case of zero net holdings of foreign bonds, $B^{*}=0$, which implies that $\phi=0$. Eqs. (28) and (29) then reduce to

$$
\begin{aligned}
& \gamma=2+i^{*}+\frac{\epsilon}{\sigma} \\
& \Delta=1+i^{*},
\end{aligned}
$$

where $\epsilon=\frac{1}{a}+\frac{1}{b}-1$ because $s=1$.

We first state the following proposition.

Proposition 1. The characteristic Eq. (27) with Eqs. (32) and (33) has two roots satisfying $|\lambda|<1$ iff 
(i) $\frac{-\epsilon}{\sigma}>0$,

(ii) $4+2 i^{*}+\frac{\epsilon}{\sigma}>0$,

(iii) $1+i *<1$, and it has two real roots $\lambda_{1}$ and $\lambda_{2}$ with $\left|\lambda_{1}\right|>1>\left|\lambda_{2}\right|$ iff

(iv-a) $\frac{-\epsilon}{\sigma}<0$,

(iv-b) $4+2 i^{*}+\frac{\epsilon}{\sigma}>0$.

Proof. According to Grandmont and Laroque (1988), the characteristic Eq. (27) has two roots satisfying $|\lambda|<1$ iff

(i) $1+\Delta-\gamma>0$,

(ii) $1+\Delta+\gamma>0$,

(iii) $\Delta<1$, and it has two real roots $\lambda_{1}$ and $\lambda_{2}$, with $\left|\lambda_{1}\right|>1>\left|\lambda_{2}\right|$ iff

(iv) $|\gamma|-|1+\Delta|>0$.

By substituting $\gamma$ and $\Delta$ into Eqs. (32) and (33), and noting that, given $\gamma>0$, the condition $|\gamma|-|1+\Delta|>0$ is equivalent to the following two inequalities,

$$
\begin{aligned}
& 1+\Delta-\gamma<0, \\
& 1+\Delta+\gamma>0,
\end{aligned}
$$

we immediately arrive at condition (i) through (iv-b) in Proposition (1).

We are now ready to consider the dynamic properties of the steady state. If the Marshall-Lerner condition is satisfied at this fixed point, that is, if $\epsilon=\frac{1}{a}+\frac{1}{b}-1>0$, it is immediately seen that condition (i) is violated and the stationary equilibrium point cannot be locally stable. On the other hand, conditions (iv-a) and (iv-b) are apparently fulfilled, implying that the Jacobian matrix evaluated at $q^{*}=1$ has one real eigenvalue greater, and the other smaller, than unity in absolute value. Woodford (1992, p. 224) calls this the case of 'saddlepoint stability': there is a unique rational expectations equilibrium and no endogenous fluctuations are possible. We therefore arrive at

Corollary 2. The steady state exhibits saddle-point properties if the Marshall-Lerner condition is satisfied.

The dynamic properties of the stationary state when the Marshall-Lerner condition is not satisfied are more interesting in that there may exist periodic cycles in its neighborhood. The existence of such periodic equilibria may be established by applying the theory of Hopf bifurcation. A Hopf bifurcation refers to the development of periodic orbits ('self-oscillations') from a stable fixed point. It occurs at a critical value of the key parameter, say $i^{*}=i_{0}^{*}$, if the corresponding eigenvalues $\lambda_{1}\left(i^{*}\right)$ and 
$\lambda_{2}\left(i^{*}\right)$ are complex conjugates and cross the unit circle at $i_{0}^{*}$. We first state the following proposition:

Proposition 3. A Hopf bifurcation occurs at $i_{0}^{*}=0$, that is, periodic orbits of the real exchange rate develop from a stable fixed point when the parameter $i^{*}$ passes the critical value $i_{0}^{*}$.

The above proposition is an application of the theorem on the existence of Hopf bifurcation (see Lorenz, 1989, pp. 96-97):

Let the mapping $q_{t+1}=H\left(q_{t}, \mu\right), q_{t} \in R^{2}, \mu \in R$, have a fixed point $q^{*}$, at which the eigenvalues are complex conjugates. If there is a $\mu_{0}$ such that

$$
\left(\bmod \lambda\left(\mu_{0}\right)\right)=1 \text { but } \lambda^{n}\left(\mu_{o}\right) \neq \pm 1, n=1,2,3,4,
$$

and

$$
\frac{\mathrm{d}(\bmod \lambda(\mu))}{\mathrm{d} \mu} \neq 0
$$

then there is an invariant closed curve bifurcating from $\mu=\mu_{0}$.

In our model $q^{*}$ is independent of $\phi, i^{*}, \alpha$ and $\beta$ under the condition that the net bond holding is nil in the stationary state. The eigenvalues are complex conjugates if

$$
-2 \sqrt{l+i^{*}}<2+i^{*}+\frac{\epsilon}{\sigma}<2 \sqrt{1+i^{*}}
$$

that is, if

$$
\frac{-\epsilon}{2+i^{*}+2 \sqrt{1+i^{*}}}<\sigma<\frac{-\epsilon}{2+i^{*}-2 \sqrt{1+i^{*}}}
$$

Assume for the moment that the inequalities (35) hold. A Hopf bifurcation occurs at

$$
i_{0}^{*}=0 \text {, }
$$

because, at $i^{*}=i_{0}^{*}$,

$\Delta=1$.

The modulus crosses the unit circle with nonzero speed when the parameter $i^{*}$ is changed:

$$
\left.\frac{\mathrm{d} \sqrt{\lambda_{1} \lambda_{2}}}{\mathrm{~d} i^{*}}\right|_{i}{ }^{*}=i_{0}^{*}=1>0 .
$$

If we assume that the iterates $\lambda^{n}, n=1, \ldots, 4$, on the unit circle remain complex conjugate roots ${ }^{7}$, then a Hopf bifurcation occurs when $i *=i_{0}^{*}$.

\footnotetext{
${ }^{7}$ By using the method suggested by Reichlin (1986, p. 95), it can be proved that the inequalities $\lambda^{n}\left(\mu_{0}\right) \neq \pm 1, n=1,2,3,4$ hold as long as $-\frac{1}{2}<\frac{\epsilon}{\sigma}<0$. Unless the degree of asset substitutability is extremely low, the equalities are impossible.
} 
Returning to the inequalities in (35), it can be easily seen that, unless $\delta$ is very small, the inequalities in (35) are very likely to hold when $i^{*}$ is close to $i_{0}^{*}$.

The stability of the bifurcated closed orbit is investigated in the next section with the aid of a computer simulation using numerical examples.

\section{Numerical examples and economic interpretation}

We have shown in the previous section that it is quite easy to detect the Hopf bifurcation by analyzing the dependence of the eigenvalues $\lambda_{1}$ and $\lambda_{2}$ of the linearized system (25) on the parameter $i^{*}$. However, Proposition 3 only established local conditions for the existence of an invariant closed curve. An invariant closed curve may be attracting or repelling and it may occur in a right or left neighborhood of $i_{0}^{*}$. Determining the property of the bifurcated periodic orbit may be very tedious. ${ }^{8}$ In this section we will observe by means of a computer experiment the property of the invariant closed curve when Hopf bifurcation occurs and offer some interpretations.

With the constraints $\beta\left(1+i^{*}\right)=1$ and $\phi=0$, Eq. (22) can be written as

$$
q_{t+1}=\alpha\left(q_{t}^{\frac{1}{b}+1}-q_{t}^{2-\frac{1}{a}}\right)+q_{t}+\left(1+i^{*}\right)\left(\frac{q_{t}^{3}}{q_{t-1}^{2}}-\frac{q_{t}^{2}}{q_{t-1}}\right) .
$$

The condition for this dynamic equation to have complex roots with unit length at a bifurcation point is $1+i^{*}=1$; that is, $i^{*}=0$. Fixing $\alpha$, $a$ and $b$, one may choose $i^{*}$ to be the bifurcation parameter. A bifurcation occurs if, as $i^{*}$ varies, $\Delta=1+i^{*}$ passes through unity. Figs. 1 and 2 graph computer simulations in the neighborhood of the stationary state. ${ }^{9}$

These figures were generated for parameter values of $\frac{1}{a}=0.6, \frac{1}{b}=0.1, \alpha=1$, and varied $\left(1+i^{*}\right)$ (or equivalently $\left.i^{*}\right)$. The initial condition for all the figures is $\left(q_{t}\right.$, $\left.q_{t+1}\right)=(0.9,0.9)$, and the number of iterations is 10,000 . Holding $a, b$, and $\alpha$ constant, a bifurcation occurs as $\left(1+i^{*}\right)$ (or $\left.i^{*}\right)$ passes through 1 (or zero). When $\left(1+i^{*}\right)$ is less than or equal to 1 or when the world interest rate is almost nil (Fig. 1), the stationary state is a stable point. It is worth noting that these trajectories were generated by a single initial condition. If $\left(1+i^{*}\right)$ is increased and passes 1 , an invariant attracting closed curve occurs (Fig. 2). It is a stable quasi-periodic limit cycle since the system 'almost' repeats itself every several periods but no state re-occurs exactly. If $\left(1+i^{*}\right)$ is further increased, we can see that the invariant circle breaks at the point of 1.069 .

\footnotetext{
${ }^{8}$ One may demonstrate analytically whether a certain invariant curve is attracting or repelling. However, this requires very lengthy computations and depends in a complicated way on "third derivatives of utility functions. Since economic theory does not place restrictions on third derivatives," Farmer (1986, p. 83) argues that "one might expect that either repelling or attracting cycles may exist."

9 These simulations are run by using the package PHASER (Koçak, 1983).
} 


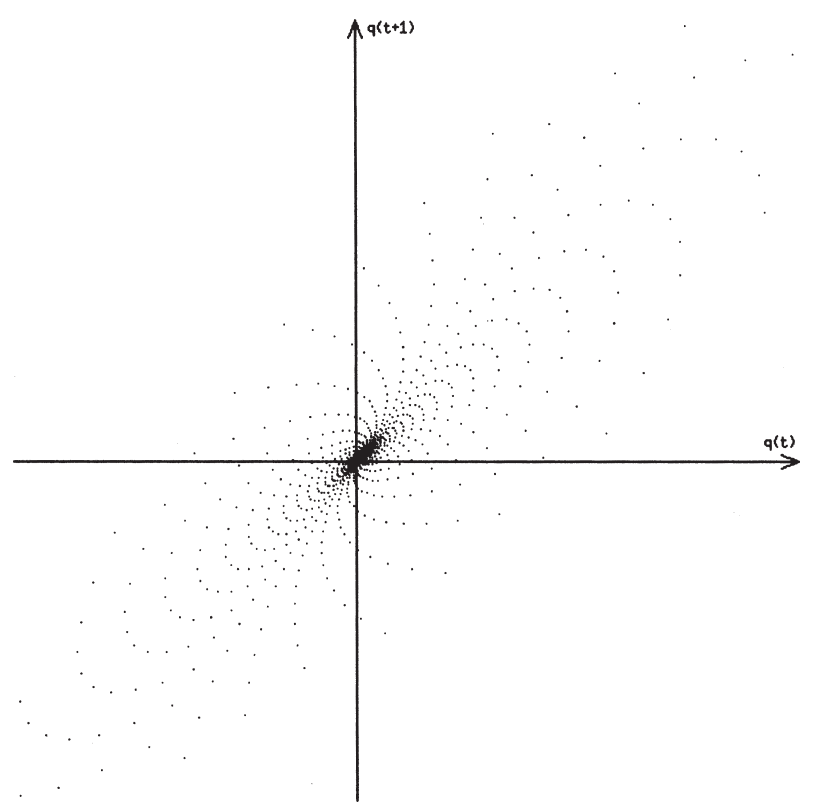

Fig. 1. An unstable cycle and a stable fixed point.

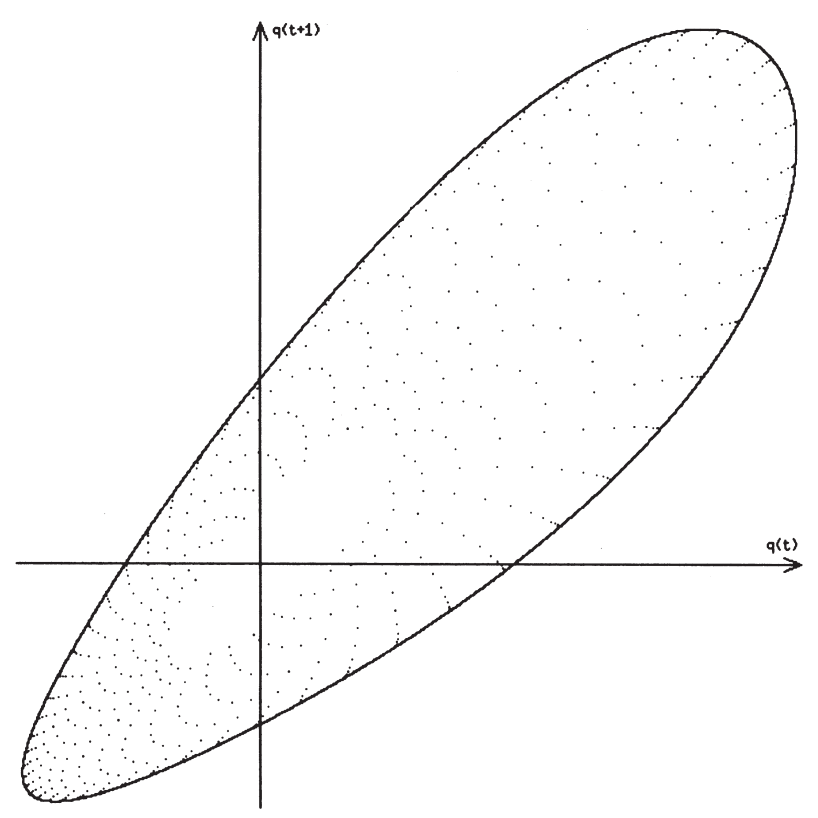

Fig. 2. A stable quasi-periodic limit cycle. 
After this point, repeated iterations eventually cause the trajectory of $\left(q_{t}, q_{t+1}\right)$ to move out of bounds.

From the numerical experiments, we conclude that, when the world interest rate, $i^{*}$, is negative, the stationary state is stable and indeterminate, and when $i^{*}$ increases and exceeds zero, the stationary state will become unstable and a stable periodic limit cycle of real exchange rates emerges. The former case is the case of indeterminacy where both eigenvalues of Eq. (27) have modulus less than unity. In this case there exists a largeset of rational expectations equilibria for each choice of $q_{0}$ near $q^{*}$, including a large set of stationary sunspot equilibria attracted to the steady state point, as shown in Fig. 1. The stationarity of sunspot-equilibria stochastic processes implies that the sunspot fluctuations do not die down in amplitude asymptotically. The latter case is the case of 'instability' where both eigenvalues have modulus greater than unity. For most initial conditions there exist no equilibria converging asymptotically to the steady state. Rather, an invariant closed curve will emerge around the steady state. If the closed curve is attracting and stable as is the case shown in Fig. 2, the perfect foresight equilibrium will be indeterminate and sunspot equilibria will exist, as Woodford $(1984,1992)$ suggests. However, in simulating the sunspot model for the case of limit cycles, one finds that unless the stochastic component is very small, the exchange rate explodes. This implies that the behavior of the real exchange rate is dominated by the deterministic cycle and is hence largely predictable-which is inconsistent with the situation in the real world, where exchange rate movements are largely unpredictable. In Section 5 we shall explore the possibility of 'local' sunspot equilibria which not face this criticism.

In the rest of this section we provide an intuitive explanation of the reason why $\epsilon<0$ is the condition necessary for generating cyclical fluctuations and why $i^{*}>0$ is the condition for the cyclical equilibrium to be locally divergent. First, note that under the assumption that $B^{*}=0$ and $q^{*}=1$ at the stationary state, linearization of Eq. (21) around the deterministic stationary state approximates the changes in various accounts of the balance-of-payments equation as,

$$
\epsilon\left(q_{t}-q^{*}\right)-\sigma\left[\left(q_{t+1}-q_{t}\right)-\left(q_{t}-q_{t-1}\right)\right]+i^{*} \sigma\left(q_{t}-q_{t-1}\right)=0
$$

The first term in this expression represents the change in the trade account, the second term represents the change in the capital account, and the last term represents the change in the service account. Rearranging the above equation, we obtain

$$
q_{t+1}-q_{t}=\left(1+i^{*}+\frac{\epsilon}{\sigma}\right)\left(q_{t}-q_{t-1}\right)+\frac{\epsilon}{\sigma}\left(q_{t-1}-q^{*}\right) .
$$

Suppose that $\epsilon>0$, and consider a competitive sequence of real exchange rates $\left\{q_{t}\right\}_{t=2}^{\infty}$ where $q_{0}=1, q_{1}>1$. In period 1 , the trade account is in surplus because the current real exchange rate $q_{1}$ exceeds the equilibrium rate $q^{*}=1$. To restore balance, the expected and actual change in the real exchange rate in period $2, q_{2}-q_{1}$, must be greater than that in period 1, so as to induce enough capital exports to offset the surplus in the current account. It is evident from (37) that 


$$
\left(q_{2}-q_{1}\right) /\left(q_{1}-q_{0}\right)=1+i^{*}+\frac{\epsilon}{\sigma}>1
$$

unless $i^{*}<-\frac{\epsilon}{\sigma}<0$, which is unlikely in reality. A real depreciation is associated with a rise in the expected rate of real depreciation. Since $q_{1}>q_{0}$ by assumption, we have

$$
q_{2}=q_{1}+\left(1+i^{*}+\frac{\epsilon}{\sigma}\right)\left(q_{1}-q_{0}\right)>q_{1}
$$

The real exchange rate in period 2 will be strictly larger than the real exchange rate in period 1. In period 2, the current account surplus will be even greater, calling for an even larger increase in the real exchange rate in period 3. It follows that $q_{3}-$ $\mathrm{q}_{2}>\mathrm{q}_{2}-\mathrm{q}_{1}$. Repeating this experiment, one may show that the real exchange rate sequence must be monotonically increasing if $q_{1}>q^{*}$, and decreasing if $q_{1}<q^{*}$. Cycles cannot occur in the neighborhood of the stationary state if export-import demands are elastic, $\epsilon>0 .{ }^{10}$

With $\epsilon<0$, this may not be the case. Consider, once again, the same real exchange rate sequence $\left\{q_{t}\right\}_{t=2}^{\infty}$ for $q_{0}=1, q_{1}>1$. In period 1 , the trade account is now in deficit due to inelastic demand $(\epsilon<0)$. For the moment, assume that $i^{*}=0$ so that the service account can be ignored. The increment in the real exchange rate between period 2 and period 1 must be smaller than that between period 1 and period 0 (or even negative), to induce enough capital imports to offset the deficit in the trade account:

$\left(q_{2}-q_{1}\right) /\left(q_{1}-q_{0}\right)=1+\frac{\epsilon}{\sigma}<1$. A deviation in the current real exchange rate from its equilibrium level pulls the change in the real exchange rate in the next period downward or even reverses its direction: $q_{2}-q_{1}<q_{1}-q_{0}$, or $q_{2}-q_{1}<0 .{ }^{11}$ Monotonic movements in the real exchange rate sequence are impossible. Rather, a cyclical equilibrium in the neighborhood of the stationary state will be generated, which may be locally either convergent or divergent. A bifurcation occurs as the stability of the equilibrating process changes. In our model economy, the bifurcation occurs at $i^{*}=0$, a point at which the service account is always zero. With $i^{*}<0$, a change in $q_{t}$ will induce a change in the service account $\left(i^{*} \sigma\left(q_{t}-q_{t-1}\right)\right)$ in the same direction as that in the trade account $\left(\epsilon\left(q_{t}-q^{*}\right)\right)$, augmenting the stabilizing effect of the negative trade balance elasticity. With $i^{*}>0$, the opposite is true. In the former case, the cycle will converge asymptotically to the stable steady state. In the latter case, an invariant cycle emerges around the unstable steady state and the cycle may be attracting or repelling.

\section{Existence of sunspot equilibria}

Under the assumption that the net asset position of the home economy is nil, it has been found in the preceding section that local sunspot equilibria exist only in

\footnotetext{
10 The method of induction is adopted from Farmer (1986).

${ }^{11} q_{2}<q_{1}$ if the degree of asset substitutability is very low, i.e., if $\sigma<-\epsilon$.
} 
the highly unrealistic case in which the interest rate on foreign bonds is zero or negative. In this section we will show that, when the home economy is structurally a net debtor, then, under the normal situation of a positive interest rate, the steady state can be stable and indeterminate and hence local sunspot equilibria can exist.

We know that the necessary condition for both eigenvalues of the Jacobian matrix in (26) to have modulus less than one is that the determinant takes a value less than unity, that is, $\Delta=(1+\phi)\left(1+i^{*}\right)<1$, which implies that $\phi<\frac{-i *}{1+i^{*}}<0$. Thus, $\phi$ and hence $\frac{\phi}{\alpha}$ have to be negative if $i^{*}$ is positive. It follows that for real exchange rate equilibria to be indeterminate, the home economy has to be a net debtor in the steady state. ${ }^{12}$

Given that $i^{*}>0$ and $\beta\left(1+i^{*}\right)=1$, we have the following proposition.

Proposition 4, The perfect foresight equilibrium of the system of Eq. (25) is stable and indeterminate if $\epsilon<0$ and $\phi<\frac{-i^{*}}{1+i^{*}}$.

Proof. We have already seen in Section 3 that both eigenvalues of the Jacobian matrix in Eq. (27) have modulus less than unity, iff (i) $1+\Delta-\gamma>0$, (ii) $1+\Delta+\gamma>0$, and (iii) $\Delta<1$. Condition (iii) is fulfilled by assumption. Substituting the value of $\Delta$ and that of $\gamma$ into condition (i), we have $1+\Delta-\gamma=-\epsilon / \sigma>0$, and given that $\gamma>0,{ }^{13}$ we have $1+\Delta+\gamma=(1+\Delta-\gamma)+2 \gamma>0$. Conditions (i) and (ii) are also satisfied.

Having established the possibility of indeterminacy for the real exchange rate in a deterministic model, we now proceed to construct a stochastic sunspot model. Based on the stochastic Euler Eqs. (4)-(7), we can write the following stochastic real exchange rate equation

$$
E_{t} q_{t+1}=\frac{\alpha q_{t}^{2}}{\beta\left(1+i^{*}\right)}\left(q_{t}^{\frac{1-b}{b}}-s q_{t}^{-\frac{1}{a}}\right)-\frac{(\phi-1) q_{t}}{\beta\left(1+i^{*}\right)}+\frac{(\phi-1) q_{t}^{2}}{\beta q_{t-1}}+\frac{\left(1+i^{*}\right) q_{t}^{3}}{q_{t-1}^{2}}
$$

This stochastic equation generalizes the deterministic Eq. (22). Linearization of this stochastic equation around the stationary state yields

\footnotetext{
12 This proposition holds for the general case, $\Delta=2\left(1+i^{*}\right)+\frac{\phi-1}{\beta}$ when $\beta\left(1+i^{*}\right) \neq 1$. Substituting the conditin $\Delta<1$ into Eq. (18), we have $q^{*} B^{*}<\frac{-i^{*} \beta}{\alpha}<0$.

$\gamma=1+(1+\phi)\left(1+i^{*}\right)+\frac{\epsilon}{\sigma}=1+(1+\phi)\left(1+i^{*}\right)+\alpha\left(s \frac{1}{a}+\frac{1}{b}-s\right)>0$ unless $\alpha$ is very large, that is, unless $\sigma(=1 / \alpha)$ is very small.
} 


$$
\begin{aligned}
& {\left[\begin{array}{l}
q_{t}-q^{*} \\
q_{t+1}-q^{*}
\end{array}\right]=\left[\begin{array}{ll}
0 & 1 \\
-\left(1+i^{*}\right)(1+\phi) & 1+\left(1+i^{*}\right)(1-\phi)+\frac{\epsilon}{\sigma}
\end{array}\right]\left[\begin{array}{l}
q_{t-1}-q^{*} \\
q_{t}-q^{*}
\end{array}\right]} \\
& +\left[\begin{array}{l}
0 \\
\eta_{t+1}
\end{array}\right]
\end{aligned}
$$

where $\eta_{t+1}$ is any random variable that is unforecastable at date $t$. We have shown that, when $\epsilon<0$ and $\phi<\frac{-i^{*}}{1+i^{*}}$, both eigenvalues of the Jacobian matrix will have modulus less than 1. If one interprets the random variable $\eta_{t+1}$ as the self-fulfilling beliefs of individual agents, then a large set of stationary sunspot equilibria may emerge near the steady state.

We now proceed to look for empirical evidence in terms of actual data. We choose Canada as a test case. The Canadian economy is suitable for testing the validity of the model. Firstly, Canada's imported goods are supplied elastically to it by the world market. Secondly, Canada is a price taker in over variables denote deviations from the following equation from (39) the international financial markets. By letting hats the steady-state value, that is, $\hat{q}_{t}=q_{t}-q^{*}$, we obtain

$$
\hat{q}_{t+1}=\left(1+\left(1+i^{*}\right)(1+\phi)+\frac{\epsilon}{\sigma}\right) \hat{q}_{t}-\left(1+i^{*}\right)(1+\phi) \hat{q}_{t-1}+\eta_{t+1}
$$

The actual data to be used for comparison with the calibrated model are the IFS quarterly data of the real effective exchange rate index (based on relative valueadded deflators) over the period 1986 through 1996. To be comparable to $q_{t}$ in our model, $q_{t}$ in this section is adjusted so as to equal 100 divided by the index. The mean of this adjusted variable over the period of 44 quarters is 1.09136 . We choose this mean value as a proxy for the steady state value, $q^{*}$. The steady-state world interest rate is set at $1 \%$ per quarter. ${ }^{14}$ The trade balance elasticity, $\epsilon$, is set at -0.3 and the degree of asset substitutability, $\sigma$, is set at 10 , that is, $\alpha=0.1$. If we arbitrarily assign the value of $\phi$ to be 0.1 , it will imply that the steady-state value of the net asset position is minus one, that is, $q^{*} B^{*}=\frac{-0.1}{0.1}=-1$, which, in our model, is equal to the value of exports, $X^{*} .{ }^{15}$ Substituting these parameter values into Eq. (40), we obtain a second order autoregressive model:

\footnotetext{
14 Schmitt-Grohé (1998) set the rate at $4 \%$ per year.

15 Observed net borrowings in Canada are much higher. However, Canada's net interest payments and net imports have been financed by net capital inflow. It is reasonable to assume that, in the steady state, the (negative) net asset position would be much lower than observed, since in the steady state, the net interest payments have to be financed by net exports.
} 


$$
\hat{q}_{t+1}=1.879 \bar{q}_{t}-0.909 \hat{q}_{t-1},
$$

whose roots in the corresponding characteristic equation are $\lambda_{1,2}=0.9395 \pm 0.1623 i$, with modulus $R=\sqrt{0.909}=0.9534$. The fact that our model is capable of generating complex roots, as will be seen immediately below, is the key to understanding why the calibrated model can capture certain dynamic features of the data nicely.

The reason why the observation period starts with the first quarter of 1986 has to do with the episode of the Plaza Accord. On September 22, 1985, the finance ministers of the Group of Five (G-5) countries-the United States, Britain, France, Germany, and Japan - announced at New York's Plaza Hotel that they would jointly intervene in the foreign exchange market to bring down the dollar. The dollar dropped drastically the next day and continued to decline through 1986. The announcement by finance ministers of exchange rate intervention must have caused drastic changes in expectations among participants in the exchange markets. We therefore regard the episode of the Plaza Accord as an impulse to the Canadian exchange market and choose the first quarter of 1986 as the beginning of the sample period. The de-meaned Canadian data (44 quarters) are plotted in Fig. 3. It can be seen that the actual fluctuations in the Canadian real exchange rate are both cyclical and volatile. The excessive volatility of the actual data can be attributed to the variances of the 'sunspots'. If fluctuations in the real exchange rate are assumed to be driven by independent and identically distributed (i.i.d.) self-fulfilling beliefs, ${ }^{16}$ we can assign the standard deviation of the sunspot disturbances a value which will cause the volatility of the real exchange rate to match the data. It is well established in time series analysis that the variance $\sigma_{y}^{2}$ of the autoregressive process of second order,

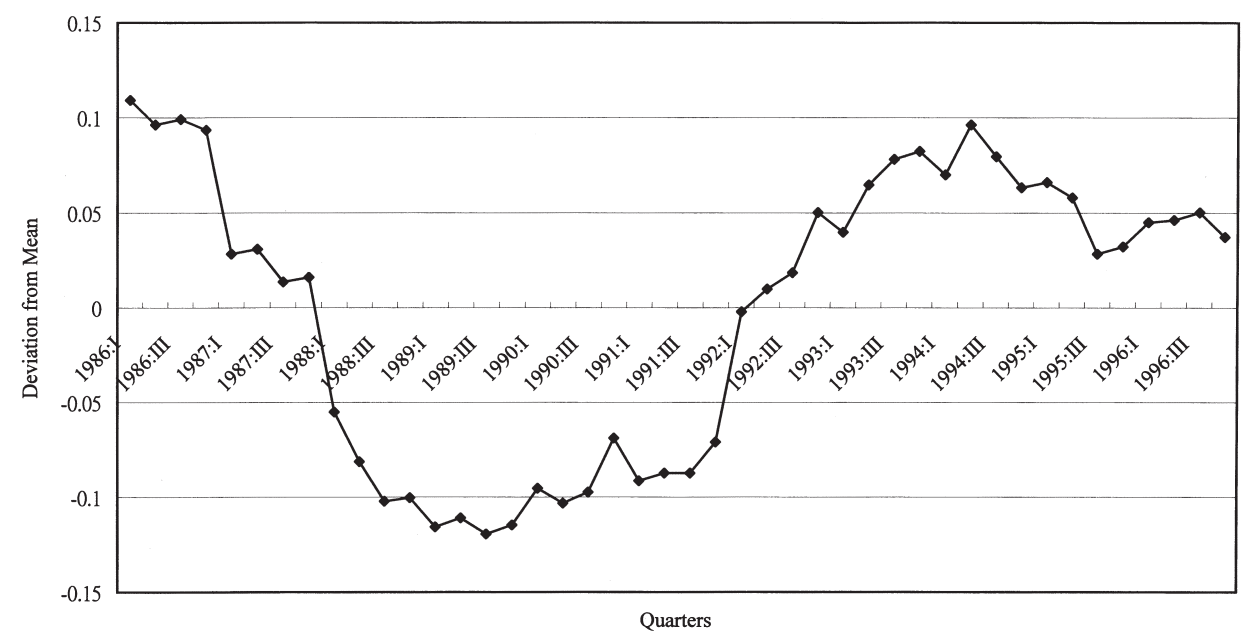

Fig. 3. Oscillations of Canada's real exchange rate from 1986 to 1996.

${ }^{16}$ Farmer and Guo (1994) make this assumption in simulating their business-cycle model. 


$$
y_{t}=\bar{y}+\phi_{1} y_{t-1}+\phi_{2} y_{t-2}+\varepsilon_{t}
$$

is

$$
\sigma_{y}^{2}=\frac{\left(1-\phi_{2}\right) \sigma_{\varepsilon}^{2}}{\left(1+\phi_{2}\right)\left[\left(1-\phi_{2}\right)^{2}-\phi_{1}^{2}\right]} .
$$

Since the second-order autoregressive process of Eq. (41) is stationary, and since the sunspots are i.i.d., with the variance of the data being $(0.074823)^{2}$, the variance of the sunspots, $\sigma_{s}^{2}$, can be derived from the above formula as

$$
\sigma_{s}^{2}=\frac{\left[(0.909)^{2}-(2.879)^{2}\right](1-0.909)(0.074823)^{2}}{(1+0.909)}=(0.00552)^{2}
$$

A standard deviation of less than $0.6 \%$ in sunspots would cause the actual variability of the real exchange rate seen in the data to have a standard deviation of $7.5 \%$.

The calibrated model also predicts the dynamic pattern of the actual data quite nicely. The complex eigenvalues of the characteristic Eq. (41) are less than one in modulus $(R=0.9534<1)$, predicting that the dynamic multiplier follows a pattern of damped oscillation as plotted in Fig. 3. The frequency of these oscillations is given by a parameter $\theta$ defined implicitly by $\cos \theta=0.9395 / 0.9534=0.9854$ or $\theta=0.175$. The cycles associated with the calibrated model thus have a period of $2 \pi / \theta=(2)(3.1416) / 0.175=35.9$; that is, the peaks of the cycle appear about 36 periods apart. The calibrated model has correctly predicted the frequency of the cycle of the actual data plotted in Fig. 3. ${ }^{17}$

\section{Concluding remarks}

Frankel and Meese (1987) and several other econometric studies suggest that actual exchange rate movements are largely not attributable to variations in macroeconomic variables (fundamentals). An endogenous, deterministic model of exchange rate dynamics such as the present one could, in principle, give a plausible explanation to this empirical finding. This paper has shown that even a simple, perfect-foresight model of a small open economy with a finite degree of asset substitutability may generate cyclical dynamic paths for the real exchange rate, when the Marshall-Lerner condition is not satisfied. The crucial point here is that, with a negative trade-balance elasticity, a higher-than equilibrium real exchange rate induces a negative trade balance, which calls for a smaller real exchange rate change in the next period. The possibility of monotonic movements of the real exchange rate is therefore excluded and cyclical fluctuations emerge. The story of real-exchange-rate endogenous fluctuations presented in this paper distinguishes itself from existing models of exchange rate dynamics, which have assumed the fulfillment of the Marshall-Lerner condition

\footnotetext{
${ }^{17}$ See Hamilton (1994, Chapter 1) for a discussion of the frequency and period of a sinusoidal function derived from a difference equation.
} 
and have a unique rational expectations equilibrium. Since the fact that the sum of short-run demand elasticities for imports and exports is less than unity is empirically well-established, our model may be interpreted as explaining short-run fluctuations in the real exchange rate as an endogenous process.

The assumption that the Marshall-Lerner condition does not hold is crucial for generating the complex dynamics of the real exchange rate in our model. Assuming that this condition does not hold is only justified if our model is viewed as a model of high frequency exchange rate movements, as empirically net exports do not respond much to exchange rate movements in the very short run. However, for most industrialized countries, the Marshall-Lerner condition does hold for adjustment periods beyond the very short run (six months). See, for example, Krugman and Obstfeld (1997, p. 485). To go beyond this short-term time frame, we will probably have to construct an open-economy endogenous growth model by incorporating physical capital accumulation, which produces differences between long-run and short-run responses of net exports to real exchange rate changes. Endogenous fluctuations in real exchange rates might occur due to specific properties of production functions rather than to the failure of the Marshall-Lerner condition.

\section{Acknowledgements}

The author would like to thank an anonymous referee for his stimulating criticisms and many perceptive and detailed comments, which substantially improved the exposition and substance of the present paper. She is also indebted to J. M. Grandmont for his generous guidance and help on an earlier version of this paper.

\section{References}

Auernheimer, L., 1987. On the outcome of inconsistent programs under exchange rate and monetary rules. Journal of Monetary Economics 19, 279-305.

Boldrin, M., Woodford, M., 1990. Equilibrium models displaying endogenous fluctuations and chaos. Journal of Monetary Economics 25, 189-222.

Brock, W.A., 1975. A simple perfect foresight monetary model. Journal of Monetary Economics 1, $133-150$.

Brock, W.A., Hsieh, D., LeBaron, B., 1991. Nonlinear Dynamics, Chaos, and Instability. MIT Press, Cambridge, MA.

Calvo, G.A., 1980. Financial opening, crawling peg and the real exchange rate. Mimeo, Centro de Estudios Macroeconomicos de Argentina.

Calvo, G.A., 1991. Temporary stabilization policy. Journal of Economic Dynamics and Controls 15, $197-213$.

Calvo, G.A., Rodriguez, C.A., 1977. A model of exchange rate determination under currency substitution and rational expectations. Journal of Political Economy 85, 617-625.

Chen, C.N., Tsaur, T.W., Liu, S.C., 1989. Currency substitution, foreign inflation and terms-of-trade dynamics. Journal of Political Economy 97, 955-964.

Dornbusch, R., 1976. Expectations and exchange rate dynamics. Journal of Political Economy 84, 1161-1176.

Farmer, R., 1986. Deficits and cycles. Journal of Economic Theory 40, 77-88. 
Farmer, R., Guo, J.T., 1994. Real business cycles and the animal spirits hypothesis. Journal of Economic Theory 63, 42-72.

Feenstra, R.C., 1985. Anticipated devaluations, currency flight, and direct trade controls in a monetary economy. American Economic Review 75, 386-401.

Frankel, J.A., 1983. Monetary and portfolio-balance models of exchange rate determination. In: Bhandari, J.S., Putnam, B.H. (Eds.), Economic Interdependence and Flexible Exchange Rates. MIT Press, Cambridge, MA.

Frankel, J.A., Meese, R., 1987. Are exchange rates excessively variable? Working Paper 2249, NBER.

Frenkel, J.A., Rodriguez, C.A., 1982. Exchange rate dynamics and the overshooting hypothesis. IMF Staff Papers 20, 1-30.

Fukuda, S., 1993. The emergence of equilibrium cycles in a monetary economy with a separable utility function. Journal of Monetary Economics 32, 321-334.

Grandmont, J.M., Laroque, G., 1988. Stability, expectations and predetermined variables. Technical Report 522, Institute for Mathematical Studies in the Social Sciences, Stanford University.

Grandmont, J.M., Younes, Y., 1972. On the role of money and the existence of a monetary equilibrium. Review of Economic Studies 39, 355-372.

Grandmont, J.M., Younes, Y., 1973. On the efficiency of a monetary equilibrium. Review of Economic Studies 40, 149-165.

Hamilton, J.D., 1994. Time Series Analysis. Princeton University Press, Princeton, NJ.

Helpman, E., Razin, A., 1982. A comparison of exchange rate regimes in the presence of imperfect capital markets. International Economic Review 23, 365-388.

Hsieh, D.A., 1989. Testing for nonlinear dependence in daily foreign exchange rates. Journal of Business 62, 339-368.

Kenen, P.B., 1985. The International Economy. Prentice-Hall, Englewood Cliffs, NJ.

Koçak, H., 1983. Differential and Difference Equations through Computer Experiments, 2nd ed. SpringerVerlag, New York.

Krugman, P.R., Obstfeld, M., 1997. International Economics, 4th ed. Harper Collins, UK.

Liviatan, N., 1981. Monetary expansion and real exchange rate dynamics. Journal of Political Economy $89,1218-1228$.

Lorenz, H.W., 1989. Nonlinear Dynamical Economics and Chaotic Motion. Lecture Notes in Economics and Mathematical Systems 334. Springer-Verlag, New York.

Meese, R., Rogoff, K., 1983. Empirical exchange rate models of the seventies: do they fit out of sample? Journal of International Economics 14, 3-24.

Mundell, R., 1973. Uncommon arguments for common currency. In: Johnson, H.G., Swoboda, A.K. (Eds.), The Economics of Common Currencies. Harvard University Press, Cambridge, MA.

Obstfeld, M., 1981. Macroeconomic policy, exchange-rate dynamics, and optimal asset accumulation. Journal of Political Economy 89, 1142-1161.

Obstfeld, M., 1997. Open-economy macroeconomics: developments in theory and policy. Working Paper 6319, NBER.

Reichlin, P., 1986. Equilibrium cycles in an overlapping generations economy with production. Journal of Economic Theory 40, 89-102.

Sargent, T.J., 1987. Dynamic Macroeconomic Theory. Harvard University Press, Cambridge, MA.

Schmitt-Grohé, S., 1998. The international transmission of economic fluctuations: effects of U.S. business cycles on the Canadian economy. Journal of International Economics 44, 257-287.

Woodford, M., 1984. Indeterminacy of equilibrium in the overlapping generations model: a survey. Unpublished paper, Columbia University.

Woodford, M., 1992. Equilibrium models of endogenous fluctuations: an introduction. In: Vercelli, A., Dimitri, N. (Eds.), Macroeconomics: A Survey of Research Strategies. Oxford University Press, New York. 